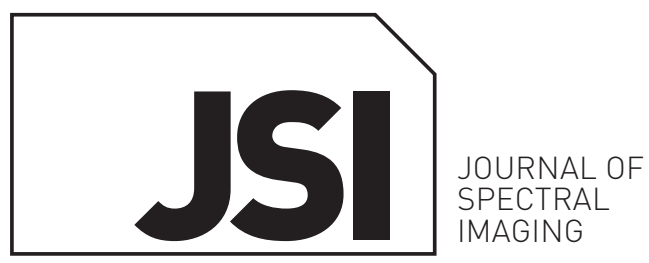

\title{
Inverting the PROSAIL canopy reflectance model using neural nets trained on streamlined databases
}

\author{
Clement Atzberger ${ }^{a}$ \\ University of Natural Resources and Life Sciences, Vienna, Institute for Photogrammetry, Land Information and Remote Sensing, Peter Jordan Strasse \\ 82,1190 Vienna, Austria. E-mail: clement.atzberger@boku.ac.at \\ ${ }^{a}$ Formerly at: Joint Research Centre of the European Commission, JRC, MARS unit, Via Enrico Fermi 2949, 21027 Ispra, Italy
}

\begin{abstract}
The widely used PROSAIL radiative transfer model was coupled with a simple soil reflectance parameterisation to estimate the leaf area index (LAI) of winter wheat (Triticum aestivum) from ground-based spectrometer data. To avoid time-consuming numerical optimisations, a neural net (NN) was used for model inversion. The NN was trained on 3000 spectral patterns generated by the reflectance model. The training database was previously streamlined to provide good approximation of the response surface while keeping the net compact. Streamlining was achieved by retaining only those synthetic spectra that belong both to the simulated and actual measurement spaces. The estimated $L A I\left(n_{\text {obs }}=15\right)$ compared well with completely independent reference measurements taken four times during the 2000 growing season in four commercial winter wheat fields $(1.8 \leq L A l \leq 8.1)$. The coefficient of determination $\left(R^{2}\right)$ between measured and estimated $L A$ / was 0.87 with a root mean squared error (RMSE) of $0.89\left(\mathrm{~m}^{2} \mathrm{~m}^{-2}\right)$. Even for $L A / \mathrm{s}$ exceeding $3-4$, saturation effects were low. Three measurement dates yielded RMSE lower than 0.8 . Only during stem elongation did RMSE exceed 1. Higher errors for this time period were attributed to abrupt changes in the canopy structure (i.e. average leaf angle) not taken into account. Compared to the normalised difference vegetation index (NDVI), the inversion of PROSAIL using hyperspectral reflectances performed well, with errors reduced by more than $50 \%$ as compared to the NDVI model (RMSE: $1.91 \mathrm{~m}^{2} \mathrm{~m}^{-2}$ ).
\end{abstract}

Keywords: artificial neural net, radiative transfer model, leaf area index, precision agriculture, Triticum aestivum, PROSPECT, SAIL, PROSAIL

\section{Introduction}

By providing both spatial and temporal information, remote sensing may function as a cost-effective source of data for precision agriculture with potentially positive benefits for both the farmer and the environment. ${ }^{1,2}$ Amongst other bio-physical variables, the leaf area index ( $L A /$ ) is an important indicator of actual crop growth, because it is related to ground coverage and photosynthetically active radiation (PAR) interception efficiency. ${ }^{3,4}$ Remotely sensed maps of the $L A l$ are therefore considered helpful for decision making and yield predictions. ${ }^{5,6}$ To assess crop productivity at regional to global scales, mapped temporal LA/ profiles were, for example, assimilated into mechanistic crop growth models ${ }^{7}$ or integrated into PAR interception formulae. ${ }^{8}$
The canopy $L A l$ can be spectrally estimated by means of empirical-statistical methods ${ }^{9,10}$ or through inversion of physically-based radiative transfer models. ${ }^{11-15}$ Most empirical-statistical methods rely on vegetation indices, either formulated using classical red and near infrared (NIR) wavebands ${ }^{16}$ or optimised through band selection in the hyperspectral feature space. ${ }^{17-19}$ Still other studies use features in the red-edge to estimate canopy bio-physical variables ${ }^{20,21}$ or establish multivariate regression approaches. ${ }^{22-24}$ The empirical-statistical approaches have the advantage that they are relatively simple and easy to use, while reasonably accurate results can be obtained. The main drawbacks of these 
methods relate to the time-consuming and labour-intensive collection of in situ calibration datasets, and the fact that the derived relationships are site- and sensor-specific. ${ }^{3}$ In the context of hyperspectral measurements, a sub-optimal use of the available spectral information is evident, in particular if the available spectral information is solely used for building (two-band) vegetation indices.

Compared to empirical-statistical approaches, radiative transfer models (RTM) consider explicitly the physical processes of light scattering and absorption within a plant canopy. ${ }^{25}$ Hence, RTMs can, in principle, be more easily transferred to different measurement conditions and crop types and are particularly well suited for hyperspectral imaging spectroscopy $^{26}$ and multi-directional data sets. ${ }^{27}$ At least three submodels are required for using $\mathrm{RTM}^{28}$ (i) a model describing the leaf optical properties, (ii) a model describing the spectral reflectance of the underlying soil background and (iii) a model describing the scattering and absorption processes within the canopy. To model the leaf optical properties, several well-established models are available, such as PROSPECT, ${ }^{29}$ LIBERTY ${ }^{30}$ or SLOP. ${ }^{31}$ Likewise, for simulating the radiative transfer in canopies, more or less complex models have been developed depending on what type of canopy is represented (for an overview see References 32 and 33). For homogeneous agricultural crops, the most widely used canopy model is the one-dimensional SAIL model. 26,34,35 For simulating complex and mixed forest stands, ray tracing models such as DART were developed. ${ }^{36}$ As these models are parameter intensive, combinations of geometrical-optical and analytical models such as INFORM were published, requiring less parameters to be specified. ${ }^{37}$ For large scale sensors typically recording the spectral signature of mixed pixels, weighting solutions were developed (for example Reference 38). To mimic the spectral reflectance of the underlying soil background, most studies simply scale a (typical) soil reflectance spectra ${ }^{15}$ or rely on the use of previously established soil lines. ${ }^{39}$ Fewer studies developed and used soil reflectance parameterisations, for example based on Hapke's soil phenomenological model. ${ }^{40,41}$

Besides the difficulty to correctly parameterise the underlying soil background reflectance, one has to deal with two main problems when using RTMs. ${ }^{25}$ First, an analytical solution of the inverse problem generally does not exist. Thus, a suitable inversion strategy has to be established..$^{11,42}$ Second, the inversion process is generally ill-posed. ${ }^{12,43}$ The ill-posedness of the inverse problem leads to unstable model inversions, since important model parameters [especially $L A I$, soil brightness and the average leaf inclination angle $(A L A)]$ counterbalance each other. ${ }^{44,45}$ To regularise the inversion, one may use prior information, for example derived from knowledge of crop type and development stage. ${ }^{12,25}$ Alternatively, it is possible to obtain additional information from the data itself, for example by analysing the colour texture of pixels representing the same agricultural field. ${ }^{43,46}$

To invert RTMs, a range of techniques has been proposed (for reviews see References 47 and 48). Early attempts relied on numerical inversion procedures. ${ }^{11,49}$ With multiple initialisations, the trapping in local minima can be avoided leading to stable results. However, this technique is too time consuming for operational applications. For this reason most studies rely on look-up-tables, LUT ${ }^{15,39,50,51}$ or artificial neural nets (NN). ${ }^{13,52-54}$ Both inversion techniques use pre-calculated (synthetic) databases, speeding up the inversion process. In the LUT approach the solution is directly found in the reflectance space, by selecting the best match between the measured reflectance values and those simulated by the RTM. ${ }^{25}$ The NN approach consists in calibrating an inverse model over the synthetic learning data set. In other words, a response surface is fitted between the reflectance values and the variable(s) of interest (here LAII. Look-up-tables are easy to implement. Drawbacks relate to the relatively large LUTs required if a dense sampling of numerous RTM parameters is necessary. The NN approach has the advantage of being extremely fast. A drawback of NNs relates to the fact that overfitting might occur, leading to poor generalisation. This happens in particular if too complex networks are employed, ${ }^{52,54}$ or if the noise structure of the remote sensing data is not correctly taken into account or even ignored. ${ }^{52,55,56}$

The main objective of the study was to present and test a robust RTM inversion procedure based on neural networks. In contrast to previous studies, special care was taken (1) to correctly mimic the soil background spectral variability found in the study area and (2) to streamline the RTM-generated synthetic database so that a small, compact net could be used for "learning" the mapping function. To correctly model the soil background reflectances, a simple soil reflectance parameterisation was calibrated using an existing (regional) soil database. To streamline the database of synthetic canopy reflectance spectra for $N N$ training, only the cases that belong both to the simulated and the actual measurement spaces were retained las suggested by Baret and Buis ${ }^{25}$ and Baret et $\left.a l^{38}\right)$. The approach was validated using destructively sampled LAl measurements taken four times in 2000 in several winter wheat fields in the western part of Germany.

\section{Material}

In 2000, four commercial winter wheat fields in the Trier area (Germany) were probed (Figure 1). Measurements were taken between mid-April and end of June (Julian day: 115, 129, 160 and 172). The test area is situated NW of Trier in an agricultural region called the "Bitburger Gutland". Eutric cambisols from airblown silt over limestone are the typical soils of the area. ${ }^{57}$ On each measurement date, a $5 \times 5 \mathrm{~m}$ plot was established in homogeneous parts of the wheat fields. Within these plots, three sub-plots were randomly chosen $(40 \times 40 \mathrm{~cm})$ in which spectral and corresponding LAl measurements were performed. The measurements from the three sub-plots were averaged to derive the observations used for modelling. On the first day of the measurement campaign, plot 4 could not be probed. Hence, the final data set consisted of $15 L A l$ and reflectance measurements. 


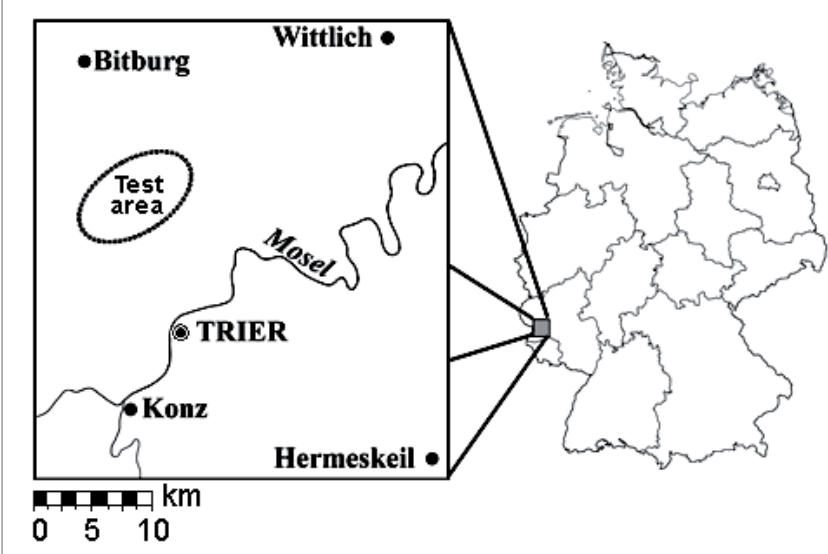

Figure 1. The study region was the "Bitburger Gutland" in Germany, north-west of the city of Trier.

\section{$L A /$ measurements}

To derive the $L A$ l observations $\left(\mathrm{m}^{2} \mathrm{~m}^{-2}\right)$, the above-ground plant material was harvested from the $40 \times 40 \mathrm{~cm}$ sub-plots and brought to the laboratory. No distinction between leaves and other green plant material (for example, stems) was made, implying that the term $L A$ l should, in the context of this study, be understood as plant area index (PAI). In the laboratory, the one-sided surface of the fresh material was determined using a commercial planimeter. From these measurements, the sub-plot land plot-averaged) LAI was derived. Measured $L A I$ values at plot level ranged between 1.8 and 8.1, with mean of 5.1 and standard deviation of 2.2 (Table 1). The temporal evolution of the measured LAls for the four winter wheat fields is shown in Figure 2(a).

\section{Canopy reflectance measurements}

Before cutting the plants for the $L A$ l measurements, the top of canopy (TOC) reflectance was recorded for each sub-plot. Spectral data were recorded between $350 \mathrm{~nm}$ and $2500 \mathrm{~nm}$ using an ASD Field Spec Pro spectroradiometer (FOV 25) with a spectral resolution of $1 \mathrm{~nm}$. The hand-held measurements were made from a height of about $1.5 \mathrm{~m}$ during favourable weather conditions around solar noon. The integration time was set to $10 \mathrm{~s}$. No corrections as to the spatial non-uniformity of different detectors within the ASD instrument were applied, albeit recent research has shown that this issue can have significant implications. ${ }^{58}$

ASD readings were converted to bi-directional reflectances by means of a Spectralon ${ }^{\circledR}$ reference panel of known reflectivity. For each sub-plot, five reflectance readings were taken and averaged, allowing the eventual detecting of outliers. A moving SG filter ${ }^{59}$ with a window width of $\pm 5 \mathrm{~nm}$ and a polynomial of second degree was applied to eliminate sensor noise. After smoothing, the spectra were averaged across the three sub-plots. For modelling, 13 bands were selected in proximity to the 10 "optimum bands" proposed by Fourty

Table 1. Descriptive statistics of the destructively measured leaf area index (LA/) of four winter wheat plots in year 2000. The table reports the minimum value (min), maximum (max), mean (mean), standard deviation (stdv) and the number of observations $\left(n_{\text {obs }}\right.$ ). Each observation corresponds to the average of three sub-plot measurements.

\begin{tabular}{|l|c|c|c|c|c|c|c|c|c|}
\hline \multicolumn{4}{|c|}{} & \multicolumn{9}{|c|}{ Julian day (JD) } & \multicolumn{4}{c|}{ Plot number } \\
\hline & All & $\mathbf{1 1 5}$ & $\mathbf{1 2 9}$ & $\mathbf{1 6 0}$ & $\mathbf{1 7 2}$ & $\mathrm{n}^{\circ} \mathbf{1}$ & $\mathrm{n}^{\circ} \mathbf{2}$ & $\mathrm{n}^{\circ} \mathbf{3}$ & $\mathrm{n}^{\circ} \mathbf{4}$ \\
\hline $\min$ & 1.81 & 1.81 & 4.94 & 3.60 & 1.99 & 3.84 & 2.10 & 1.81 & 2.73 \\
\hline $\max$ & 8.12 & 3.84 & 7.73 & 8.12 & 7.63 & 8.12 & 6.65 & 4.94 & 6.59 \\
\hline mean & 5.05 & 2.58 & 6.22 & 6.24 & 4.54 & 6.83 & 5.25 & 3.08 & 5.04 \\
\hline stdv & 2.22 & 1.10 & 1.18 & 1.90 & 2.64 & 2.01 & 2.13 & 1.48 & 2.04 \\
\hline$n_{\text {obs }}$ & 15 & 3 & 4 & 4 & 4 & 4 & 4 & 4 & 3 \\
\hline
\end{tabular}
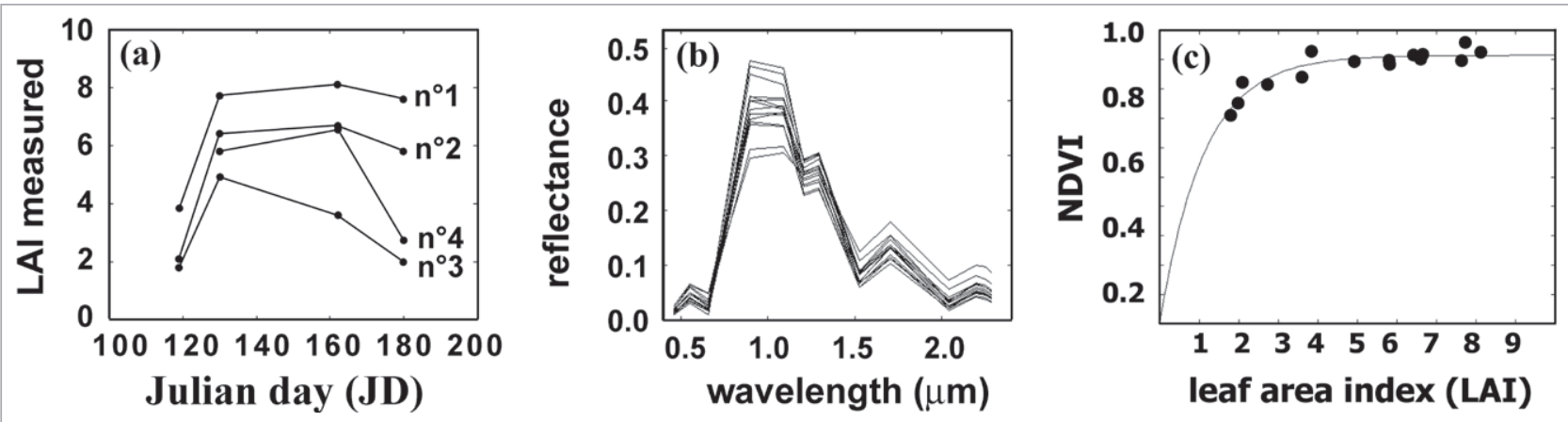

Figure 2. Field observations available for the 2000 winter wheat study: (a) temporal profiles of destructively sampled leaf area indices ( $L A /$ ) for the four wheat plots (note the missing observation of field number 4), (b) corresponding field-measured canopy reflectance spectra in 13 wavelengths specified in Table 2, (c) experimental relation between $L A /$ and NDVI (dots) together with an exponential fit (line). 
Table 2. Spectral sampling applied to the experimental study. In total, 13 wavelengths were used (left). The listed wavelengths (in $\mathrm{nm}$ ) are close to the ten "optimum" wavebands proposed by Fourty and Baret. ${ }^{60}$ The first three channels (corresponding to Landsat TM bands 1 to 3 ) were added to cover the visible range. Right: corresponding HyMap channel number.

\begin{tabular}{|c|c|}
\hline $\begin{array}{c}\text { Spectral sampling for } \\
\text { radiative transfer modelling } \\
\text { (forward and inverse) }\end{array}$ & $\begin{array}{c}\text { Corresponding channel } \\
\text { number of the HyMap } \\
\text { sensor }\end{array}$ \\
\hline $\begin{array}{c}457 ; 549 ; 656 ; 896 ; 1089 ; \\
1207 ; 1293 ; 1527 ; 1706 ; 2042 ;\end{array}$ & $\begin{array}{c}3 ; 9 ; 16 ; 33 ; 46 ; 54 ; 60 ; \\
2201 ; 2254 ; 2288\end{array}$ \\
\hline
\end{tabular}

and Baret $^{60}$ plus three additional bands in the visible (corresponding to the central wavelengths of Landsat bands 1 to 3). The 13 wavelengths were fixed to the central wavelengths of the nearest HyMAP channels, for eventual later application of the trained network to the widely flown HyMAP sensor ITable 2). The measured canopy spectra in these wavelengths are shown in Figure 2(b). Figure 2(c) gives an idea of the scatter between the field-measured LAls and normalised difference vegetation index (NDVI).

\section{Methods}

The extensively exploited PROSAIL radiative transfer model was used to retrieve the $L A l$ from the spectrometer data ${ }^{40}$ (http://teledetection.ipgp.jussieu.fr/prosail/). PROSAIL is a combination of the SAILH canopy reflectance model ${ }^{34,61}$ and the PROSPECT leaf optical properties model, version 4.29 Both sub-models are relatively simple and require only a limited number of input parameters. PROSAIL was successfully validated in forward and inverse modes, and across different crops including maize, sugar beet and wheat. ${ }^{26,33}$ To mimic the reflectance variability of the underlying soil background, a simple soil parameterisation (SOILEMP) was developed and coupled with PROSAIL. Model inversions were performed using artificial neural nets. To streamline the simulated training data, we followed Baret and Buis. ${ }^{25}$ The general approach is outlined in Figure 3. The different steps will be detailed in the following sub-sections.

\section{Soil parameterisation}

The canopy reflectance is known to be modulated by the underlying soil brightness. ${ }^{3}$ The soil effect is strongest for small canopy densities $(L A l<3)$ and in spectral regions with high leaf transmittance (Figure 4). To correctly mimic the soil reflectance variability found in the study region, a simple soil parameterisation (SOILEMP) was developed. SOILEMP considers (1) changes in the overall brightness and (2) changes in the shape of the reflectance curves related to variations in the inorganic carbon content of the soils in the study region. Other factors possibly modifying the spectral shape of the soil reflectance in the study area were neglected.

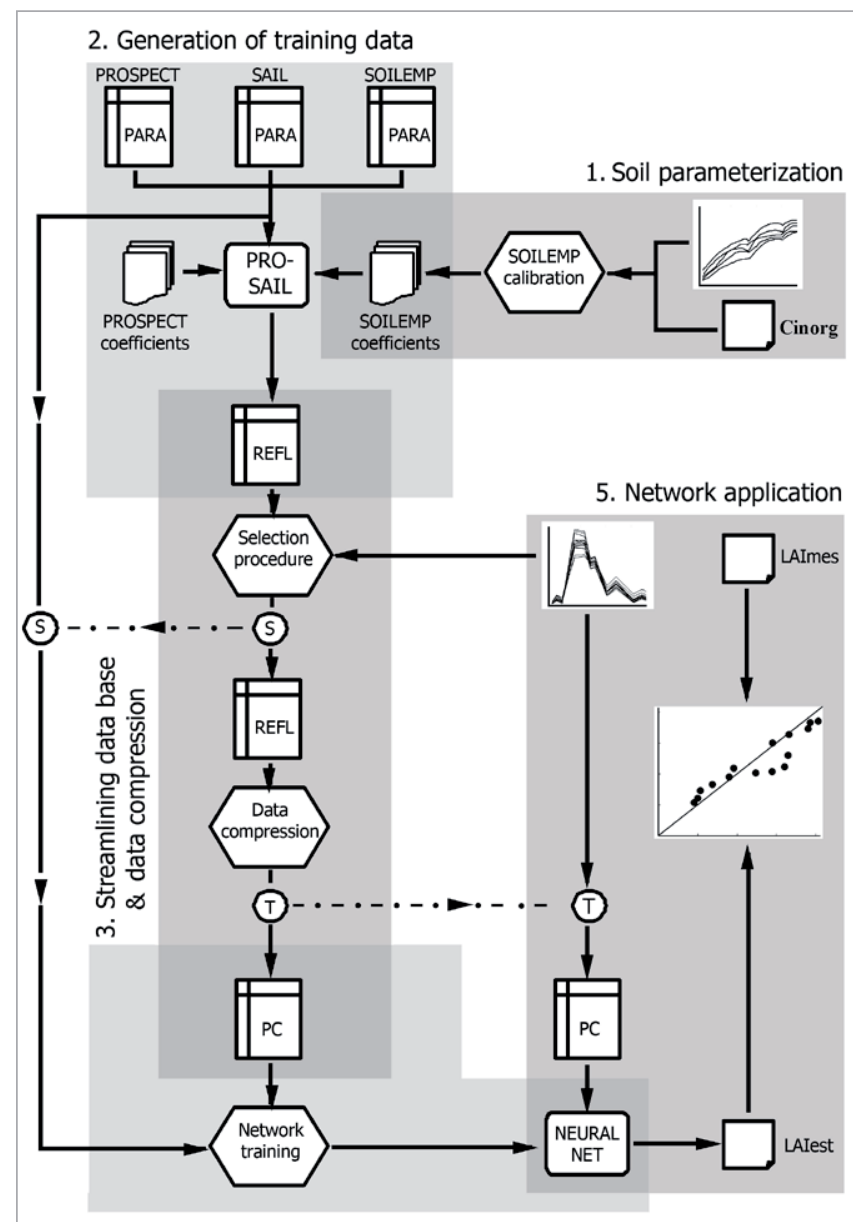

4. Network training

Figure 3. General flowchart of the NN-based inversion of the PROSAIL radiative transfer model. In the first step, the regression coefficients of the SOILEMP soil reflectance parameterisation are calibrated. For this purpose, measured soil reflectance spectra and laboratory measured soil inorganic carbon contents $\left(C_{\text {inorg }}\right.$ ) are used [Equations ( 1 ) and (2)]. In the second step, the randomly drawn parameters (PARA) of the three sub-models representing the leaf, soil and canopy optical properties are used to generate a synthetic canopy reflectance database (REFL). In the third step, the synthetic canopy reflectance database (REFL) is streamlined (S), so that only those simulations are retained that match with measured spectra. The reduced database is hereafter subjected to a principal component analysis (PCA), yielding the transformation matrix (T) and the first six principal components (PC). These PCs are used in step 4 to train the neural network. Once trained, the neural net is applied in step 5 to measured canopy spectra, previously transformed into PCs to yield the estimated $L A I\left(L A I_{\text {est }}\right)$. These estimated $L A I$ can be compared with the field measured $L A I\left(L A I_{\text {mes }}\right)$ to assess the accuracy of the RTM inversion for field measured canopy reflectance spectra.

To calibrate the SOILEMP parameterisation a soil database of the study region was used. ${ }^{57}$ The database covers soils from the entire study region and consists of 134 soil spectra at $1 \mathrm{~nm}$ resolution and associated chemical measurements. From the database, the average soil spectra $\left(\rho_{\text {soil( } \lambda)}^{*}\right)$ was calculated. This 


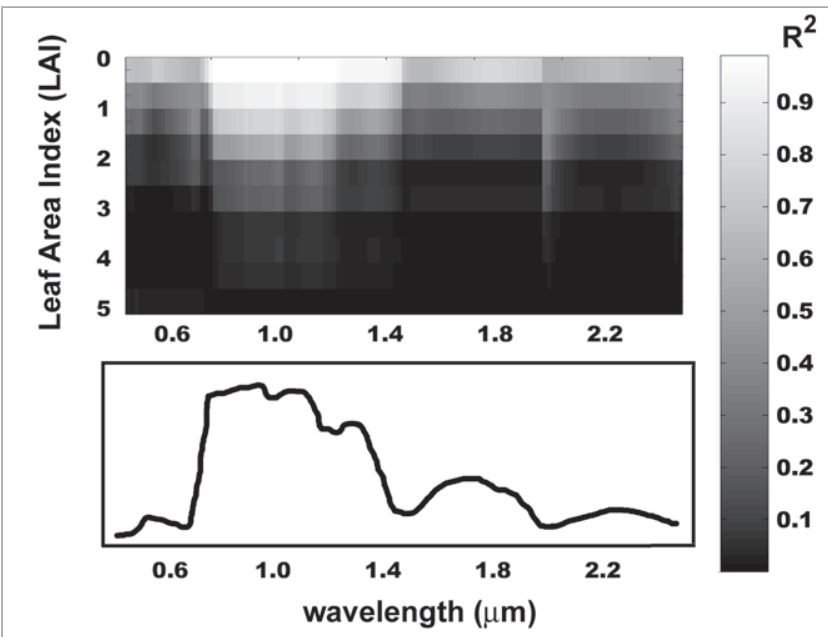

Figure 4. Sensitivity analysis illustrating the strength of the soil background effect on simulated TOC reflectances in 128 HyMap channels and for ten different canopy densities (here expressed as $L A / l$ ). A typical vegetation spectrum is indicated for orientation purposes. The strength of the soil background effect is expressed as $R^{2}$ between soil brightness and TOC reflectance for a given spectral band and within a specific $L A I$ range (for example, between 0 and $0.5,0.5$ and $1.0, \ldots, 4.5$ and 5.0). The synthetic database $\left(n_{\text {obs: }}: 5000\right)$ specified in Table 3 was used for analysis. Note that the wavelengths are only indicated for orientation purposes; the graphs are constructed band-by-band.

average reflectance spectrum was then (iteratively) fitted into each measured soil spectra using a (multiplicative) brightness factor (SCALE). The residues (Rsd) between the fitted (scaled) and the original soil spectra were calculated for each wavelength and modelled as a function of the inorganic carbon content $\left(C_{\text {inorg }} ; \mathrm{g} \mathrm{cm}^{-3}\right)$ :

$$
\operatorname{Rsd}_{(\lambda)}=I_{(\lambda)}+S_{(\lambda)} \times C_{\text {inorg }}
$$

The soil parameterisation therefore scales and shapes the average soil spectrum using a brightness factor (SCALE) and the inorganic carbon content $\left(C_{\text {inorg }}\right)$ :

$$
\rho_{\text {soil }(\lambda)}=\rho_{\text {soil }(\lambda)}^{*} \times S C A L E+R s d_{(\lambda)}
$$

with $I_{(\lambda)}, S_{(\lambda)}$ and $\rho_{\text {soill( })}^{*}$ being spectral constants.
Albeit simple, SOILEMP explained the major part of the total variance in the (regional) soil database [Figure 5(a)]. The coefficient of determination $\left(R^{2}\right)$ between measured soil reflectances and fitted values was 0.999 with a root mean squared error (RMSE) of 0.003 reflectance units ( $n_{\text {obs }}=17.018$ ). Only a few soil samples had spectral properties that were modelled with $R^{2}$ lower than 0.995 [Figure 5(b)], and most wavelengths were modelled with $R^{2}>0.98$ [Figure 5(c)]. Lower accuracies were found in the visible spectral region, as the effects of iron oxides and other soil constituents that modify the soil reflectance at shorter wavelengths ${ }^{62-64}$ were not taken into account.

\section{Direct and inverse canopy reflectance modelling}

Generation of training patterns

The coupled PROSAIL+SOILEMP canopy reflectance model was run in forward mode with 5000 randomly chosen input parameter sets (Table 3). The distributions of the input parameters were defined according to the literature to represent more or less erectophile wheat canopies (ALA 70 ${ }^{\circ} .{ }^{42} \mathrm{~A}$ small random error was added to the simulated spectra to mimic sensor noise. ${ }^{38}$

\section{Streamlining the training database and data compression}

To prevent network overfitting, it is recommended to restrict as much as possible the number of neurons in the hidden layer. ${ }^{13,65}$ With compact networks, however, one automatically loses flexibility in the fitted response surface. This loss in flexibility will be especially harmful if the reflectance/parameter spaces of the synthetic data set are unnecessarily large. In this case the NN will be forced to learn the relationship between input reflectances and RTM parameters outside the space it will encounter during network application. This will lead to a loss of approximation power in the reflectance space occupied by the reflectance measurements. Following Baret and Buis, ${ }^{25}$ we thus streamlined the synthetic database generated by the RTM. Among the 5000 simulated spectra only those cases were retained that belong both to the simulated and actual measurement spaces. This was achieved by computing the mismatch (here minimum RMSE) between the ensemble of
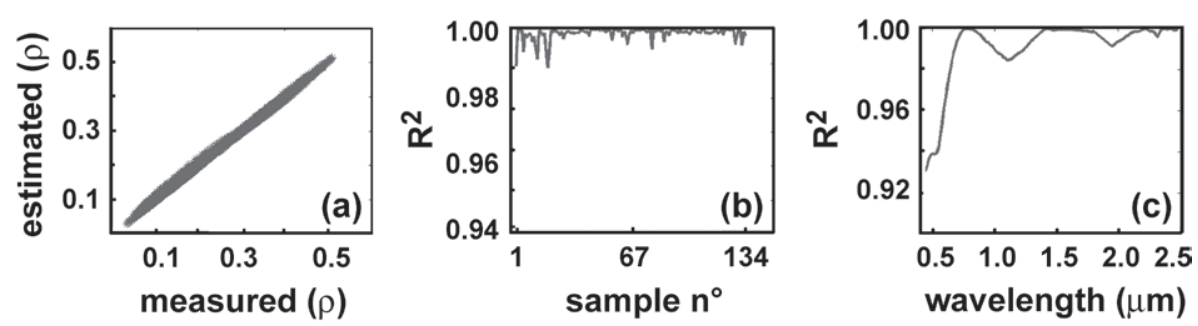

Figure 5. Calibration results of the empirical SOILEMP soil reflectance parameterisation. (a) Scatter plot between measured and fitted soil reflectances pooled across all soil samples and all wavebands, (b) sample-specific coefficient of determination $\left(R^{2}\right)$ between measured and fitted soil spectra, (c) wavelength-specific $R^{2}$ between measured and fitted soil reflectances across all soil samples. 
Table 3. Specification of the parameters of the PROSAIL+SOILEMP model used to simulate TOC reflectance spectra in 13 wavelengths for modelling erectophile winter wheat canopies (nadir view; $\theta_{z}=45^{\circ}$ ). A total number of 5000 parameter sets were randomly generated.

\begin{tabular}{|c|c|c|c|c|}
\hline RTM parameter & Abbreviation & Units & Distribution & Range $^{a}$ \\
\hline \multicolumn{5}{|c|}{ Canopy parameter (SAILH) } \\
\hline Leaf area index & $L A I$ & $m^{2} m^{-2}$ & uniform & $0-10$ \\
\hline Average leaf angle & $A L A$ & $\circ$ (degree) & normal & $70 \pm 3$ \\
\hline Hot spot parameter & S & $\mathrm{m} \mathrm{m}^{-1}$ & normal & $0.1 \pm 0.02$ \\
\hline \multicolumn{5}{|c|}{ Leaf parameter (PROSPECT) } \\
\hline Leaf chlorophyll content & $C_{a b}$ & $\mathrm{~g} \mathrm{~cm}^{-2}$ & uniform & $10-80$ \\
\hline Leaf water content & $C_{\mathrm{w}}$ & $\mathrm{cm}$ & uniform & $0.004-0.044$ \\
\hline Leaf dry matter content ${ }^{b}$ & $C_{m}$ & $\mathrm{~g} \mathrm{~cm}^{-2}$ & normal & $0.0008-0.016$ \\
\hline Leaf structure parameter & $N$ & no dimension & normal & $2 \pm 0.34$ \\
\hline \multicolumn{5}{|c|}{ Soil parameter (SOILEMP) } \\
\hline Soil brightness & SCALE & no dimension & normal & $1 \pm 0.14$ \\
\hline Inorganic carbon content & $C_{\text {inorg }}$ & $\mathrm{g} \mathrm{cm}^{-3}$ & uniform & $0-6$ \\
\hline
\end{tabular}

an cases, where the distribution is uniform. Otherwise, the values indicate the mean \pm std

${ }^{b} C_{m}$ is drawn such that the relative water content $\left[R W C=C_{w} /\left(C_{w}+C_{m}\right)\right]$ is $0.8 \pm 0.02$.

actual measurements and each case in the simulated database. Simulated spectra that were not matched by measured data were discarded. In this way, roughly 3000 reflectance spectra were retained. This (reduced) synthetic database was subjected to a PCA. The first six PCs covered more than $99.6 \%$ of the total spectral variance. Only these PCs were used further. As a matter of course, later inversion of measured spectra required the same wavelength selection and compression (indicated through dashed lines in the flowchart of Figure 3).

\section{Network training}

The NN was set up under Matlab 7 (The Mathworks, Natick, MA, USA) in a way that five parameters of the canopy reflectance model were estimated simultaneously: LAl, canopy chlorophyll content, leaf water content, leaf dry matter content and the soil brightness factor. By estimating five variables simultaneously, over-specialisation was avoided. Analysis, however, considered only $L A l$ as no reference measurements were available for the remaining variables. The NN was trained using the streamlined and compressed database described before. A compact network with just two neurons in the hidden layer was chosen. For robust training, the synthetic data set was divided into training data ( $2 / 3$ of samples) and test data ( $1 / 3$ of samples). The training data was used for computing the gradient and updating the network weights and biases. The error on the test data set was monitored during the training process. When the test data error increased for a specified number of iterations, the training was stopped, and the weights and biases at the minimum of the test data error were returned. This way of network regularisation is known as "early stopping" and effectively prevents overfitting. ${ }^{50,65}$ Further details of the network architecture and the employed network training are summarised in Table 4.

\section{Baseline comparison: NDVI}

For comparison purposes, the classical NDVI ${ }^{16}$ was used. To estimate $L A$ / from NDVI, it was assumed that the relationship between the canopy $L A /$ and the NDVI can be described by the following exponential relationship: $:^{25}$

$$
N D V I=N D V I_{\infty}+\left(N D V I_{\text {soil }}-N D V I_{\infty}\right) \times e^{-k \times L A l}
$$

To make the results of the empirical approach comparable to those of the physically-based technique, a jacknife approach (leave-one-out) was chosen for modelling. The three parameters of Equation (3) were fitted iteratively using 14 out of 15 observations. The inverse of Equation (3) was then used to estimate the LAl from the NDVI value of the left-out sample. In case the measured NDVI was higher than the estimated infinite $N D V I$, the estimated $L A /$ was set to the upper bound $(L A l=10)$. After calibration of the 15 empirical models, the cross-validated RMSE and $R^{2}$ were calculated between the field measured $L A l$ and the cross-validated estimates.

\section{Results}

The network-based inversion of the extended PROSAIL canopy reflectance model was generally successful (Table 5). The estimated $L A / s$ compared well with the independent reference measurements, with most points falling close to the $1: 1$ line (Figure 6). In total, $87 \%$ of the variance in the independent reference measurements was explained by the canopy reflectance 
Table 4. Main characteristics of the artificial neural net (MATLAB's Neural Network Toolbox; Reference 65) employed for RTM inversion.

\begin{tabular}{|l|l|}
\hline \multicolumn{1}{|c|}{ NN architecture } & \multicolumn{1}{c|}{ NN training } \\
\hline $\begin{array}{l}\text { Network type } \\
\text { Fully interconnected feedforward network }\end{array}$ & $\begin{array}{l}\text { Training patterns } \\
\text { Linearly transformed synthetic PROSAIL+SOILEMP } \\
\text { canopy spectra (13 wavelengths reduced to six PCs) and } \\
\text { associated model parameters ( } n_{\text {obs }} \sim 3000 \text { ) }\end{array}$ \\
$\begin{array}{l}\text { Three layers: input layer (six neurons), hidden layer (two } \\
\text { neurons) and output layer (five neurons; only the output } \\
\text { neuron representing the LA/ was used for subsequent } \\
\text { analysis) }\end{array}$ & $\begin{array}{l}\text { Backpropagation training algorithm } \\
\text { Levenberg-Marquardt algorithm }\end{array}$ \\
$\begin{array}{l}\text { Transfer functions of neurons in hidden and output } \\
\text { layers }\end{array}$ & $\begin{array}{l}\text { Network performance function } \\
\text { Tan-sigmoid (hidden neurons) and linear loutput neurons) } \\
\text { targets }\end{array}$ \\
& $\begin{array}{l}\text { Network generalisation } \\
\text { Automatic stop of network training when error on inde- } \\
\text { pendent test data set increased ("early stopping") } \\
\text { Simultaneous fitting of several output variables to prevent } \\
\text { overspecialisation } \\
\text { Use of noisy training patterns to avoid overfitting }\end{array}$ \\
& $\begin{array}{l}\text { Number of training iterations } \\
50 \text { or less (i.e. when "early stopping" criterion applies) }\end{array}$ \\
\hline
\end{tabular}

model ( $\left.n_{\text {obs }}=15\right)$, with a RMSE of $\left.0.89(L A) ; \mathrm{m}^{2} \mathrm{~m}^{-2}\right)$ (Table 5). This corresponds to a relative RMSE of about $17 \%$. When the NDVI was used for $L A$ I retrieval, the cross-validated RMSE was more than twice as high: $1.91 \mathrm{~m}^{2} \mathrm{~m}^{-2}$ with $R^{2}$ of 0.46 . The classical NDVI approach failed in particular for samples with $L A l>3.5$ due to saturation effects [Figure 2(c)].

Although field measured $L A /$ were as high as $L A I \sim 8$, saturation effects were only small when using the RTM approach (Figure 6). However, a general tendency to underestimate $L A$ l was noticed (i.e. $\Delta$ mean $=0.32$ ) (Table 5). The bias was particularly strong during stem elongation (JD 129) suggesting that during this period the selected $A L A\left(70 \pm 3^{\circ}\right)$ was too low. For the four individual wheat plots, the RMSE varied between 0.52 (plot 3) and 1.28 (plot 4) with $R^{2}$ between 0.69 (plot 2) and 0.99 (plot 1) (Table 5 and Figure 7). As only three to four measurements were available per wheat field, these differences should, however, not be overvalued.

\section{Discussion}

Accurate forward modelling is of prime importance when using radiative transfer models for $L A l$ retrieval. ${ }^{49}$ The RTM should be well adapted for the type of canopy studied (for example regarding the canopy architecture) and should be correctly parameterised. For relatively homogeneous crops such as the studied winter wheat plots, PROSAIL is considered well suited. ${ }^{26,33}$ In fact, several studies demonstrated its good

Table 5. Statistics between independent reference $L A l$ measurements and estimated $L A I$. The estimates were obtained using a neural net trained on linearly transformed synthetic canopy reflectance spectra, generated by the extended PROSAIL radiative transfer model. The reference measurements are from an independent validation data set ("Bitburger Gutland"). The table reports the coefficient of determination $\left(R^{2}\right)$, the root mean squared error (RMSE), the percental root mean squared error (i.e. $P R M S E=R M S E /$ mean), the difference of mean [i.e. $\Delta$ mean $=\operatorname{mean}($ measured $)-$ mean(estimated $)]$ and the number of observations $\left(n_{\mathrm{obs}}\right)$.

\begin{tabular}{|l|c|c|c|c|c|c|c|c|c|}
\hline & & \multicolumn{4}{|c}{ Julian day (JD) } & \multicolumn{4}{c|}{ Plot number } \\
\hline & All & 115 & 129 & 160 & 172 & $\mathrm{n}^{\circ} \mathbf{1}$ & $\mathrm{n}^{\circ} \mathbf{2}$ & $\mathrm{n}^{\circ} \mathbf{3}$ & $\mathrm{n}^{\circ} \mathbf{4}$ \\
\hline$R^{2}$ & 0.87 & 0.95 & 0.82 & 0.88 & 0.99 & 0.99 & 0.69 & 0.93 & 0.85 \\
\hline RMSE & 0.89 & 0.57 & 1.37 & 0.77 & 0.51 & 0.58 & 1.07 & 0.52 & 1.28 \\
\hline PRMSE & 17.6 & 22.2 & 22.1 & 12.3 & 11.1 & 8.5 & 13.1 & 16.9 & 25.4 \\
\hline$\Delta$ mean & 0.32 & -0.53 & 1.22 & 0.49 & -0.11 & 0.32 & 0.27 & -0.00 & 0.83 \\
\hline$n_{\text {obs }}$ & 15 & 3 & 4 & 4 & 4 & 4 & 4 & 4 & 3 \\
\hline
\end{tabular}




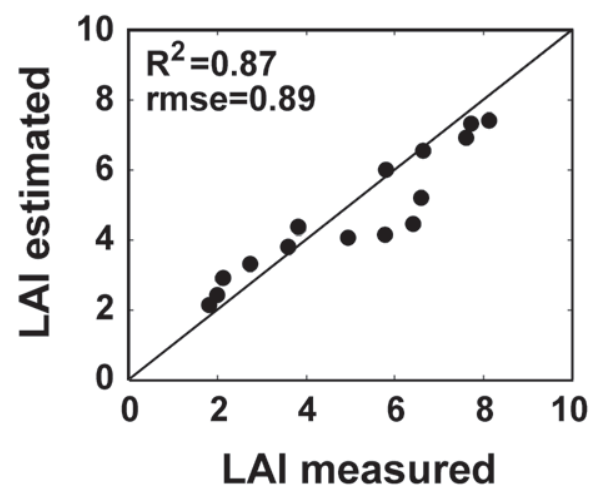

Figure 6. Scatterplot between modelled and independent LAI measurements. For modelling, the PROSAIL model was inverted using the proposed NN-based technique.

simulation power both in the spectral domain and regarding the bidirectional reflectance distribution function (BRDF). ${ }^{33}$ To further increase the simulation accuracy of the RTM in the forward mode, a regional soil reflectance parameterisation was developed and coupled with PROSAIL (Figure 5). As demonstrated by a small sensitivity analysis (Figure 4), these efforts are justified by the strong impact of the underlying soil brightness on the simulated canopy reflectance, in particular for wavelengths with high leaf transmittance (for example in the NIR) and for low to medium density canopies. Through calibration of the regional soil parameterisation, we were able to better mimic the spectral effects of the underlying soil background compared to the usual approach which simply scales a given soil spectrum. Compared to the use of more sophisticated soil reflectance models, for example based on Hapke's theory, ${ }^{41}$ the proposed approach is easier to implement.

To improve the inversion of RTMs and to prevent bias in the estimated model parameters, an appropriate band selection is recommended. ${ }^{37,47,66}$ We used as a basis a (10-band) set developed on PROSAIL by Fourty and Baret $^{60}$ (Table 2). Three bands in the visible were also added to this band set to cover this important spectral domain. Before modelling, the 13 bands were further condensed through PCA. The concentration on the most pertinent spectral bands avoided eventually occurring problems with bands not well simulated by PROSAIL. ${ }^{15,39}$ The use of a small number of (uncorrelated) spectral inputs is generally recommended in NN-based model inversions. ${ }^{47}$

The inversion of canopy reflectance models is seriously hampered by the ill-posedness of the inverse problem. ${ }^{25,67}$ The ill-posedness results mainly from counterbalancing effects between $L A l$, average leaf angle and soil brightness. ${ }^{43}$ With the present study, problems were minimised by fixing the average leaf angle (ALA) to a value representative for erectophile wheat canopies (Table 3). In an operational application of (hyperspectrall remote sensing, such a simple solution of the ill-posed inverse problem is unrealistic as a perfect knowledge of crop type and development stage cannot always be asserted. This makes continued research in this area necessary. ${ }^{46,68}$ This was, however, out of the scope of the present study. The good results obtained with a unique ALA value of about $70^{\circ}$ demonstrate

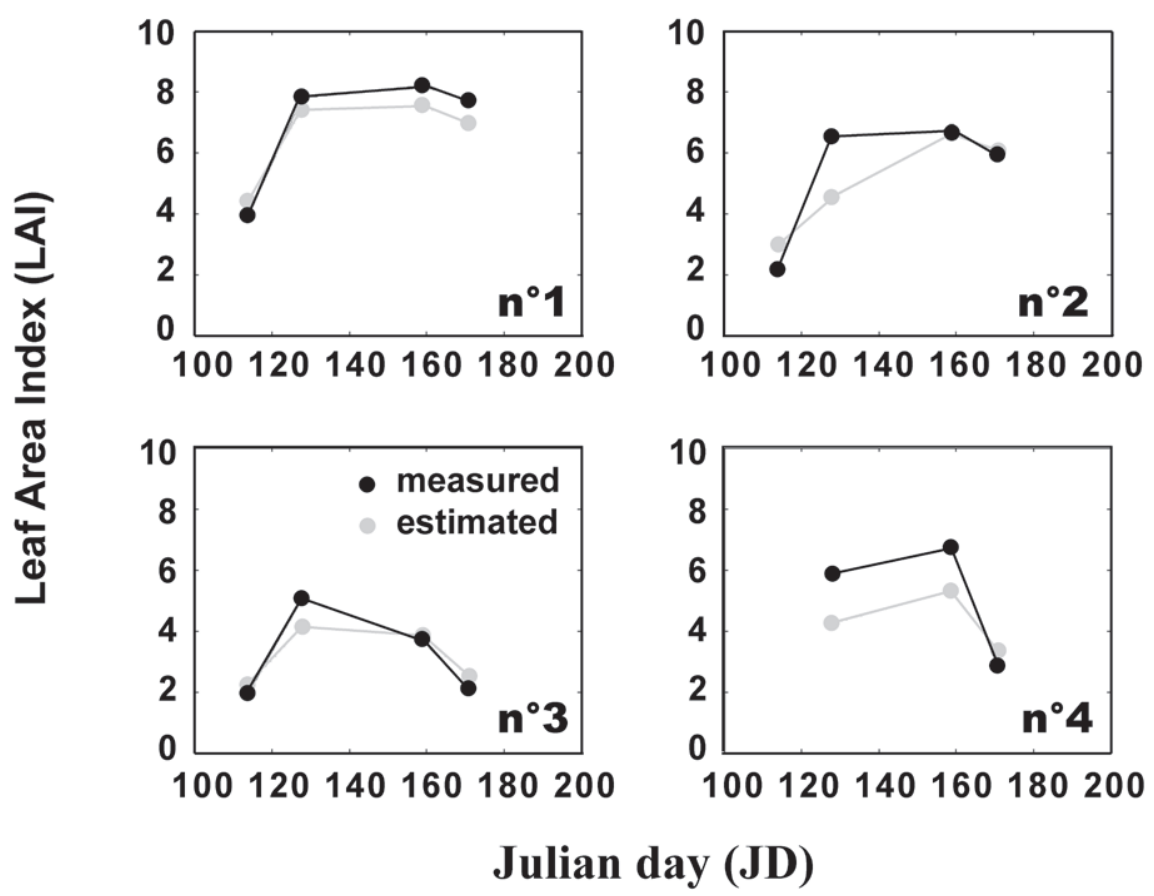

Figure 7. Time profiles of modelled (PROSAIL inversion) and measured $L A /$ for four winter wheat plots in 2000. 
that this value is appropriate for winter wheat during most of the growing cycle (except stem elongation).

Neural nets are recognised as universal function approximators. ${ }^{69}$ Their speed makes them particularly appealing candidates for processing large amounts of data encountered in imaging spectroscopy. ${ }^{70}$ However, to prevent network overfitting, the number of neurons in the hidden layer must be kept low. A drawback of compact networks is, of course, that they are less flexible concerning the fitted response surface. This loss in flexibility will be especially harmful if the reflectance/ parameter spaces of the synthetic data set are unnecessarily large. In this case the NN will be forced to learn the relationship between input reflectances and RTM parameters outside the space it will encounter during network application. This will lead to a loss of approximation power in the reflectance space occupied by the reflectance measurements. Following Baret and Buis ${ }^{25}$ and Baret et al., ${ }^{38}$ in the present study the synthetic database generated by the RTM was streamlined using the field-measured reflectance spectra. This enabled using a very compact network with only two hidden neurons (Table 4), while keeping a good learning behaviour. Overfitting and overspecialisation were further reduced through a number of other recommended techniques: ${ }^{38,53,55,70}$ (i) early stopping, (ii) simultaneous retrieval of several RTM parameter and (iii) addition of noise to the synthetic spectra before network training.

The obtained RMSE of $0.89 \mathrm{~m}^{2} \mathrm{~m}^{-2}$ across four winter wheat fields and four measurement dates (Table 5) confirms the findings of several previous studies, for example RMSE $=0.85^{19}$ and 0.64 for wheat, ${ }^{51} 0.44$ for wheat, maize and sunflower, ${ }^{71}$ and 0.74 for wheat, maize and barley ${ }^{14}$ to mention only the most successful studies. Only under exceptional circumstances, errors (here relative RMSE) lower than 10\% can be achieved; more realistic errors seem to be between $10 \%$ and $20 \%$. On the other hand, our study clearly demonstrated that the physically-based approach using RTM outperformed the classical NDVI. For the latter approach the RMSE was more than twice as high as compared to the RTM inversion. In the jacknife approach, for several samples no adequate (exponentiall models could be developed, due to the evident saturation effects [Figure 2(c)].

A more detailed look on the RTM-based results shows that most points fall relatively close to the 1-to-1 line (Figure 6) with, however, some noticeable (negative) bias (Table 5). Part of this bias must be attributed to the fact that the field sampling included both green leaves and stems. Thus, in the stricter sense, the reference surfaces correspond to a "plant area index" (PA/) instead of to a "leaf area index", with PAl>LAl. Concerning the spectral signature, however, a given stem surface has a much smaller impact compared to the same amount of leaves, because of their more or less vertical orientation. This fact probably explains the observed offset between the field measured " $L A l$ " and the retrieved values, observed for many of the higher $L A$ / values. A second factor explaining the observed underestimation concerns the selected value of the average leaf angle. The ALA value was fixed to $70^{\circ}$ independent of phenology. Such a fixed $A L A$ is probably not appropriate for all observation dates. In fact, Figure 7 and Table 5 show that the deviations between observed and simulated $L A$ / were particularly strong during stem elongation (JD 129). Probably, during this period the selected $A L A\left(70 \pm 3^{\circ}\right)$ was too low. A strong underestimation of $L A /$ during the reproductive period was also found by Haboudane et al. ${ }^{19}$ No efforts were undertaken to vary $A L A$ as a function of plant phenology, mainly because not enough samples were available.

\section{Conclusions}

The study confirmed that hyperspectral information is necessary to derive winter wheat $L A /$ with acceptable accuracy from spectral data. The classical two-band NDVI failed to correctly estimate $L A I$. To fully exploit available hyperspectral information, the use of radiative transfer models is preferred over empirical techniques (for example, PLS, PCR or MLSR). This statement is supported by several facts: (i) RTMs allow more physical insight into the system, (ii) the non-linear relations between canopy variables and spectral-directional features are implicitly taken into account, (iii) different band settings and observation geometries can be easily handled and (iv) the RTMs rely, to a lesser extent, on in situ data for model calibration.

Our results prooved that neural nets can be efficiently used for RTM inversion. However, a successful implementation of the network-based approach requires some attention. Care is necessary as these universal function approximators tend to overfit the data. This happens generally if too many neurons in the hidden layer are used. In this respect, the described approach proofed successful. The streamlined synthetic database permitted the development of a compact and robust neural net with only two neurons in the hidden layer but a good generalisation capacity. Compared to completely independent reference measurements, the $L A$ / was estimated with a $R^{2}$ of 0.87 and a RMSE of $0.89 \mathrm{~m}^{2} \mathrm{~m}^{-2}$ ( $\left.n_{\text {obs }}=15\right)$. Although the field measured $L A / s$ were as high as $L A / \sim 8$, almost no saturation effects were observed. Moreover, the temporal patterns were also relatively well reconstructed. Only during stem elongation, significant undererstimations of the estimated $L A / s$ were observed, highlighting the need for ALA values varying with crop phenology.

The relatively high accuracies found in the study demonstrate that the coupled SAILH+PROSPECT canopy reflectance model is well suited for the estimation of winter wheat $L A l$ and its temporal evolution. The effective use of the canopy reflectance model required, however, an accurate parameterisation of the underlying soil reflectance. In this study, a simple empirical soil reflectance parameterisation was integrated into PROSAIL. Prior to integration, the parameterisation was calibrated on soil spectra typical for the study region. At present, the parameterisation considers variations in overall brightness (nonspecifically related to changes in soil moisture, soil roughness and organic carbon content) and allows some variations in the spectral shape related to the soil composition (here inorganic carbon content). In particular for studying incomplete 
canopies, a better description of the underlying soil optical properties seems mandatory. Future research should focus on the development of a (physically-based) soil reflectance model allowing the simulation of spectral-directional reflectances with only a few parameters, similar to the PROSPECT model for leaf optical properties.

\section{Acknowledgements}

I would like to thank T. Jarmer, S. Mader, A. Marx, J. Krause and $W$. Werner for help in acquiring the field data. Thanks to $T$. Udelhoven for providing access to the regional soil database. The access to the wheat fields accorded by the land owners is also acknowledged. The research was partly funded by DFG through SFB 522 "Umwelt und Region".

\section{References}

1. S. Cox, "Information technology: the global key to precision agriculture and sustainability", Comput. Electron. Agric. 36, 93-111 (2002). doi: 10.1016/S01681699(02)00095-9

2. J.K. Schueller, "A review and integrating analysis of spatially-variable control of crop production", Fert. Res. 33, 1-34 (1992). doi: 10.1007/BF01058007

3. F. Baret and G. Guyot, "Potentials and limits of vegetation indices for LAI and APAR assessment", Remote Sens. Environ. 35, 161-173 (1991). doi: 10.1016/00344257(91)90009-U

4. R.B. Myneni, G. Asrar, D. Tanré and B.J. Choudhury, "Remote sensing of solar radiation absorbed and reflected by vegetated land surfaces", IEEE Trans. Geosci. Remote Sens. 30(2), 302-314 (1992). doi: $\underline{10.1109 / 36.134080}$

5. S.M. Moran, Y. Inoue and E.M. Barnes, “Opportunities and limitations for image-based remote sensing in precision crop management", Remote Sens. Environ. 61, 319-346 (1997). doi: 10.1016/S0034-4257(97)00045-X

6. J.L. Hatfield and P.J. Pinter, Jr, "Remote sensing of crop protection", Crop Prot. 12(6), 403-413 (1993). doi: 10.1016/0261-2194(93)90001-Y

7. R. Delécolle, S.J. Maas, M. Guérif and F. Baret, "Remote sensing and crop production models: present trends", ISPRS J. Photogramm. 47, 145-161 (1992). doi: 10.1016/0924-2716(92)90030-D

8. B. Leblon, M. Guérif and F. Baret, "The use of remotely sensed data in estimation of PAR use efficiency and biomass production of flooded rice", Remote Sens. Environ. 38, 147-158 (1991). doi: 10.1016/0034-4257(91)90076-1

9. N.H. Broge and E. Leblanc, "Comparing prediction power and stability of broadband and hyperspectral vegetation indices for estimation of green leaf area index and canopy chlorophyll density", Remote Sens. Environ. 76, 156-172 (2001). doi: 10.1016/50034-4257(00)00197-8
10. R. Colombo, D. Bellingeri, D. Fasolini and C.M. Marino, "Retrieval of leaf area index in different vegetation types using high resolution satellite data", Remote Sens. Environ. 86, 120-131 (2003). doi: 10.1016/S00344257(03)00094-4

11. N.S. Goel, "Models of vegetation canopy reflectance and their use in estimation of biophysical parameters from reflectance data", Remote Sens. Rev. 4, 1-112 (1987).

12. B. Combal, F. Baret, M. Weiss, A. Trubuil, D. Macé, A. Pragnère, R. Myneni, Y. Knyazikhin and L. Wang, "Retrieval of canopy biophysical variables from bidirectional reflectance using prior information to solve the illposed inverse problem", Remote Sens. Environ. 84, 1-15 (2003). doi: 10.1016/S0034-4257(02)00035-4

13. F.M. Danson, C.S. Rowland and F. Baret, "Training a neural network with a canopy reflectance model to estimate crop leaf area index", Int. J. Remote Sens. 24(23), 4891-4905 (2003). doi: 10.1080/0143116031000070319

14. R. Houborg and E. Boegh, "Mapping leaf chlorophyll and leaf area index using inverse and forward canopy reflectance modeling and SPOT reflectance data", Remote Sens. Environ. 112(1), 186-202 (2008). doi: 10.1016/j.rse.2007.04.012

15. K. Richter, C. Atzberger, F. Vuolo, P. Weihs and G. D'Urso, "Experimental assessment of the Sentinel-2 band setting for RTM-based LAl retrieval of sugar beet and maize", Can. J. Remote Sens. 35(3), 230-247 (2009).

16. C.J. Tucker, "Red and photographic infrared linear combinations for monitoring vegetation", Remote Sens. Environ. 8(2), 127-150 (1979). doi: 10.1016/00344257(79)90013-0

17. P.S. Thenkabail, R.B. Smith and E. De-Pauw, "Hyperspectral vegetation indices and their relationships with agricultural crop characteristics", Remote Sens. Environ. 71, 158-182 (2002). doi: 10.1016/S00344257(99)00067-X

18. G. Le Maire, C. François, K. Soudani, D. Berveiller, J.-Y. Pontailler, N. Bréda, H. Genet, H. Davi and E. Dufrêne, "Calibration and validation of hyperspectral indices for the estimation of broadleaved forest leaf chlorophyll content, leaf mass per area, leaf area index and leaf canopy biomass", Remote Sens. Environ. 112(10), 38463864 (2008). doi: 10.1016/j.rse.2008.06.005

19. D. Haboudane, J.R. Miller, E. Pattey, P.J. Zarco-Tejada and I.B. Strachan, "Hyperspectral vegetation indices and novel algorithms for predicting green LAI of crop canopies: Modeling and validation in the context of precision agriculture", Remote Sens. Environ. 90, 337-352 (2004). doi: 10.1016/i.rse.2003.12.013

20. R.A. Jago, M.E.J. Cutler and P.J. Curran, “Estimating canopy chlorophyll concentration from field and airborne spectra", Remote Sens. Environ. 68(3), 217-224 (1999). doi: 10.1016/S0034-4257(98)00113-8

21. M. Cho, A. Skidmore and C. Atzberger, "Towards rededge positions less sensitive to canopy biophysical 
parameters for leaf chlorophyll estimations using properties optique spectrales des feuilles (PROSPECT) and scattering by arbitrarily inclined leaves (SAILH) simulated data", Int. J. Remote Sens. 29(7/8), 2241-2255 (2008). doi: 10.1080/01431160701395328

22. C. Walthall, W. Dulaney, M. Anderson, J. Norman, H. Fang and S. Liang, "A comparison of empirical and neural network approaches for estimating corn and soybean leaf area index from Landsat ETM+ imagery", Remote Sens. Environ. 92(4), 465-474 (2004). doi: 10.1016/j. rse.2004.06.003

23. R. Darvishzadeh, A.K. Skidmore, M. Schlerf, C. Atzberger, F. Corsi and M.A. Cho, "LAl and chlorophyll estimated for a heterogeneous grassland using hyperspectral measurements", ISPRS J. Photogramm. 63(4), 409-426 (2008). doi: 10.1016/j.isprsjprs.2008.01.001

24. C. Atzberger, F. Baret, M. Guerif and W. Werner, "Comparative analysis of three chemometric techniques for the spectroradiometric assessment of canopy chlorophyll content in winter wheat", Comput. Electron. Agric. 73, 165-173 (2010). doi: 10.1016/j.compag.2010.05.006

25. F. Baret and S. Buis, "Estimating canopy characteristics from remote sensing observations. Review of methods and associated problems", in Advances in Land Remote Sensing: System, Modeling, Inversion and Application, Ed by S. Liang. Springer BV, Dordrecht, The Netherlands, pp. 172-301 (2008).

26. S. Jacquemoud, W. Verhoef, F. Baret, C. Bacour, P.J. Zarco-Tejada, G.P. Asner, C. François and S.L. Ustin, "PROSPECT + SAIL models: A review of use for vegetation characterization", Remote Sens. Environ. 113 (Suppl. 1), S56-S66 (2009). doi: 10.1016/j.rse.2008.01.026

27. S. Liang, A. Straher, M. Bernsly, C. Borel, S. Gerstl, F. Prata and C. Walthall, "Multiangle remote sensing: Past and future", Remote Sens. Rev. 18, 83-102 (2000).

28. W.A. Dorigo, R. Zurita-Milla, A.J.W. de Wit, J. Brazile, R. Singh and M.E. Schaepman, "A review on reflective remote sensing and data assimilation techniques for enhanced agroecosystem modelling", Int. J. Appl. Earth Obs. 9(2), 165-193 (2007). doi: 10.1016/j.jag.2006.05.003

29. S. Jacquemoud and F. Baret, "PROSPECT: A model of leaf optical properties spectra”, Remote Sens. Environ. 34, 75-91 (1990). doi: $10.1016 / 0034-4257(90) 90100-Z$

30. T.P. Dawson, P.J. Curran and S.E. Plummer, "LIBERTY_Modeling the effects of leaf biochemical concentration on reflectance spectra", Remote Sens. Environ. 65(1), 50-60 (1998). doi: 10.1016/S0034-4257(98)00007-8

31. S.W. Maier, W. Luedeker and K.P. Guenther, "SLOP: A revised version of the stochastic model for leaf optical properties", Remote Sens. Environ. 68(3), 273-280 (1999). doi: 10.1016/S0034-4257(98)00118-7

32. J.-L. Widlowski, M. Taberner, B. Pinty, V. Bruniquel-Pinel, M. Disney, R. Fernandes, J.-P. Gastellu-Etchegorry, N. Gobron, A. Kuusk, T. Laverne, A. Lee, R. Thompson, W. Verhoef and D. Xie, "Third radiation transfer model intercomparison (RAMI) exercise: Documenting progress in canopy reflectance models", J. Geophys. Res. D:

Atmospheres 112(9), art. no. D09111 (2007).

33. S. Jacquemoud, C. Bacour, H. Poilvé and J.-P. Frangi, "Comparison of four radiative transfer models to simulate plant canopies reflectance: Direct and inverse mode", Remote Sens. Environ. 74, 471-481 (2000). doi: 10.1016/S0034-4257(00)00139-5

34. W. Verhoef, "Light scattering by leaf layers with application to canopy reflectance modeling: the SAIL model", Remote Sens. Environ. 16, 125-141 (1984). doi: 10.1016/0034-4257(84)90057-9

35. A. Kuusk, "A fast, invertible canopy reflectance model", Remote Sens. Environ. 51(3), 342-350 (1995). doi: 10.1016/0034-4257(94)00059-V

36. V. Demarez, J.-P. Gastellu-Etchegorry, P. Mordelet, C. Tosca, G. Marty and P. Guillevic, "Modeling of the radiation regime and photosynthesis of a finite canopy using the DART model. Influence of canopy architecture assumptions and border effects", Agronomie 20(3), 259 270 (2000). doi: 10.1051/agro:2000125

37. M. Schlerf and C. Atzberger, "Inversion of a forest reflectance model to estimate structural canopy variables from hyperspectral remote sensing", Remote Sens. Environ. 100(3), 281-294 (2006). doi: 10.1016/j. rse.2005.10.006

38. F. Baret, O. Hagolle, B. Geiger, P. Bicheron, B. Miras, M. Huc, B. Berthelot, F. Niño, M. Weiss, O. Samain, J.L. Roujean and M. Leroy, "LAI, fAPAR and fCover CYCLOPES global products derived from VEGETATION. Part 1: Principles of the algorithm", Remote Sens. Environ. 110(3), 275-286 (2007). doi: 10.1016/j. rse.2007.02.018

39. R. Darvishzadeh, A.K. Skidmore, M. Schlerf and C. Atzberger, "Inversion of a radiative transfer model for estimating vegetation LAl and chlorophyll in a heterogeneous grassland", Remote Sens. Environ. 112(5), 2592 2604 (2008). doi: 10.1016/i.rse.2007.12.003

40. S. Jacquemoud, F. Baret, B. Andrieu, M. Danson and K. Jaggard, "Extraction of vegetation biophysical parameters by inversion of the PROSPECT+SAIL models on sugar beet canopy reflectance data. Application to TM and AVIRIS sensors", Remote Sens. Environ. 52, 163-172 (1995). doi: 10.1016/0034-4257(95)00018-V

41. W. Verhoef and H. Bach, “Coupled soil-leaf-canopy and atmosphere radiative transfer modeling to simulate hyperspectral multi-angular surface reflectance and TOA radiance data", Remote Sens. Environ. 109(2), 166182 (2007). doi: 10.1016/j.rse.2006.12.013

42. A. Bsaibes, D. Courault, F. Baret, M. Weiss, A. Olioso, F. Jacob, O. Hagolle, O. Marloie, N. Bertrand, V. Desfond and F. Kzemipour, "Albedo and LAl estimates from FORMOSAT-2 data for crop monitoring", Remote Sens. Environ. 113, 716-729 (2009). doi: 10.1016/i. rse.2008.11.014

43. C. Atzberger, "Object-based retrieval of biophysical canopy variables using artificial neural nets and radiative 
transfer models", Remote Sens. Environ. 93, 53-67 (2004). doi: 10.1016/j.rse.2004.06.016

44. R. Darvishzadeh, C. Atzberger, S. van Wieren and A. Skidmore, "Estimation of vegetation LAl from hyperspectral reflectance data: effects of soil type and plant architecture", Int. J. Appl. Earth Obs. 10(3), 358-373 (2008). doi: 10.1016/j.jag.2008.02.005

45. R. Houborg, M. Anderson and C. Daughtry, "Utility of an image-based canopy reflectance modeling tool for remote estimation of LAl and leaf chlorophyll content at the field scale", Remote Sens. Environ. 113(1), 259-274 (2009). doi: 10.1016/j.rse.2008.09.014

46. C. Atzberger and K. Richter, "Geostatistical regularization of inverse models for the retrieval of vegetation biophysical variables", Proc. SPIE 7478, 74810 (2009). doi: 10.1117/12.830009

47. D. Kimes, Y. Knjazikhin, J.L. Privette, A. Abuelgasim and F. Gao, "Inversion methods for physically-based models", Remote Sens. Rev. 18, 381-440 (2000).

48. S. Liang, "Recent developments in estimating land surface biogeophysical variables from optical remote sensing", Prog. Phys. Geog. 31(5), 501-516 (2007). doi: 10.1177/0309133307084626

49. N.S. Goel, "Inversion of canopy reflectance models for estimation of biophysical parameters from reflectance data", in Theory and Applications of Optical Remote Sensing, Ed by G. Asrar. John Wiley \& Sons Inc., New York, USA, pp. 205-251 (1989).

50. M. Weiss, F. Baret, R.B. Myneni, A. Pragnere and Y. Knyazikhin, "Investigation of a model inversion technique to estimate canopy biophysical variables from spectral and directional data", Agronomie 20, 3-22 (2000). doi: 10.1051/agro:2000105

51. K. Richter, C. Atzberger, F. Vuolo and G. D'Urso, “LAI retrieval accuracy for different crops from future ESA Sentinel-2 satellite", IEEE Journal of Selected Topics in Earth Observation and Remote Sensing, accepted (2010). doi: 10.1109/JSTARS.2010.2091492

52. A.A. Abuelgasim, S. Gopal and A.H. Strahler, "Forward and inverse modelling of canopy directional reflectance using a neural network", Int. J. Remote Sens. 19, 453-471 (1998). doi: 10.1080/014311698216099

53. C. Bacour, F. Baret, D. Béal, M. Weiss and K. Pavageau, "Neural network estimation of LAI, fAPAR, fCover and LAl×Cab, from top of canopy MERIS reflectance data: Principles and validation", Remote Sens. Environ. 105(4), 313-325 (2006). doi: 10.1016/j.rse.2006.07.014

54. P. Gong, D.X. Wang and S. Liang, "Inverting a canopy reflectance model using neural network”, Int. J. Remote Sens. 20, 111-122 (1999). doi: 10.1080/014311699213631

55. P.M. Atkinson and A.R.L. Tatnall, "Neural networks in remote sensing", Int. J. Remote Sens. 18(4), 699-709 (1997). doi: $\underline{10.1080 / 014311697218700}$

56. T. Udelhoven, C. Atzberger and J. Hill, “Retrieving structural and biochemical forest characteristics using artificial neural networks and physically based reflectance models", in A Decade of Trans-European Remote Sensing Cooperation, Ed by M.F. Buchroithner. A.A. Balkema, Leiden, The Netherlands, pp. 205-211 (2000).

57. T. Udelhoven, C. Emmerling and T. Jarmer, "Quantitative analysis of soil chemical properties with diffuse reflectance spectrometry and partial-least-square regression", Plant Soil 251(2), 319-329 (2003). doi: 10.1023/A:1023008322682

58. A.A. MacArthur, C. MacLellan and T.J. Malthus, "The implications of non-uniformity in fields-of-view of commonly used field spectroradiometers", Geoscience and Remote Sensing Symposium, 2007. IEEE International, California, USA, pp. 2890-2893 (2007). doi: 10.1109/ IGARSS.2007.4423447

59. A. Savitzky and M.J.E. Golay, "Smoothing and differentation of data by simplified least square procedure", Anal. Chem. 36, 1627-1638 (1964). doi: $\underline{10.1021 /}$ ac60214a047

60. T. Fourty and F. Baret, "Vegetation water and dry matter contents estimated from top-of-the-atmosphere reflectance data: A simulation study", Remote Sens. Environ. 61, 34-45 (1997). doi: 10.1016/S0034-4257(96)00238-6

61. A. Kuusk, "The hot spot effect in the leaf canopy", in Geoscience and Remote Sensing Symposium, 1991. IGARSS 91. Remote Sensing: Global Monitoring for Earth Management. IEEE International, California, USA, pp. 1555-1557 (1991).

62. M.F. Baumgardner, L.F. Silva, L.L. Biehl and E. Stoner, "Reflectance properties of soils", Adv. Agron. 38, pp. 1-44 (1985). doi: 10.1016/S0065-2113(08)60672-0

63. E. Ben-Dor, S. Chabrillat, J.A.M. Demattê, G.R. Taylor, J. Hill, M.L. Whiting and S. Sommer, "Using imaging spectroscopy to study soil properties", Remote Sens. Environ. 113(Suppl. 1), S38-S55 (2009). doi: 10.1016/j. rse.2008.09.019

64. J. Farifteh, F. van der Meer, M. van der Meijde and C. Atzberger, "Spectral characteristics of salt-affected soils: A laboratory experiment", Geoderma 145(3/4), 196-206 (2008). doi: 10.1016/j.geoderma.2008.03.011

65. H. Demuth and M. Beale, Neural Network Toolbox for use with MATLAB. The Mathworks, Inc., MA, USA (1998).

66. M. Meroni, R. Colombo and C. Panigada, "Inversion of a radiative transfer model with hyperspectral observations for LAI mapping in poplar plantations", Remote Sens. Environ. 92(2), 195-206 (2004). doi: 10.1016/j. rse.2004.06.005

67. N.S. Liang, Quantitative Remote Sensing of Land Surfaces. John Wiley and Sons, Inc., New York, USA (2004).

68. C. Lauvernet, F. Baret, L. Hascoët, S. Buis and F.-X. Le Dimet, "Multitemporal-patch ensemble inversion of coupled surface-atmosphere radiative transfer models for land surface characterization", Remote Sens. Environ. 112(3), 851-861 (2008).

69. K. Hornik, M. Stinchcombe and H. White, "Multilayer feedforward networks are universal approximators", 
Neural Networks 2(5), 359-366 (1989). doi: 10.1016/0893$\underline{6080(89) 90020-8}$

70. D.S. Kimes, R.F. Nelson, M.T. Manry and A.K. Fung,

"Attributes of neural networks for extracting continuous vegetation variables from optical and radar measurements", Int. J. Remote Sens. 19(14), 2639-2663 (1998). doi: $10.1080 / 014311698214433$

71. M. Weiss, F. Baret, M. Leroy, O. Hautecœur, C. Bacour, L. Prévot and N. Bruguier, "Validation of neural net techniques to estimate canopy biophysical variables from remote sensing data", Agronomie 22(6), 547-553 (2002). doi: 10.1051/agro:2002036 